\title{
Valuation for Cigarettes among University of the Philippines Manila Students through Stated Preference Methods
}

\author{
John Paul Caesar R. delos Trinos, ${ }^{1}$ Liana Mae J. Lobo,,${ }^{1,2}$ Charmaine Joy A. Cabaña, ${ }^{1,3}$ \\ Shermaine Anne B. De Leon, ${ }^{1,4}$ Abigail Ann A. Guiñez ${ }^{1,5}$ and Abubakar S. Asaad ${ }^{1}$ \\ ${ }^{1}$ College of Public Health, University of the Philippines Manila \\ ${ }^{2}$ College of Medicine, University of the Philippines Manila \\ ${ }^{3}$ Ateneo School of Medicine and Public Health \\ ${ }^{4}$ St. Louis University-School of Medicine \\ ${ }^{5}$ University of the East Ramon Magsaysay Memorial Medical Center
}

\begin{abstract}
Objective. The study aimed to assess the valuation for cigarettes among UP Manila students aged 18-24 through direct and indirect stated preference methods.

Methods. Direct (iterative bidding) and indirect (discrete choice experiment) stated preference methods were utilized to determine the smokers' Willingness-to-Pay (WTP) and nonsmokers' Willingness-to-Accept (WTA). Median and interquartile range were used in describing both WTP and WTA. Fisher's Exact Test and T-test were performed using STATA v12 to determine the association between the identified factors.
\end{abstract}

Results. Of the 212 respondents, 21 (9.91\%) were smokers. The smokers' direct and indirect WTP for a cigarette stick were PhP 6.00 and PhP 12.43, respectively. There was a significant difference $(p=0.01)$ between the results of the two methods. Meanwhile, $40.84 \%$ of the non-smokers could be induced to smoke with $\mathrm{PhP} 0.00$ as their WTA. No significant association was found between the smokers' stated preference and their smoking status and allowance. The WTP of the smokers was higher than the December 2013 retail prices of cigarettes.

Conclusion. The increased cigarette prices brought about by the Sin Tax Law were insufficient in stopping the selected UP Manila students to smoke. In addition, forty percent of non-smokers in the study could be induced to smoke. Thus, further price increase of cigarettes, as well as other tobacco control measures, is recommended to discourage smoking among the youth such as college students, specifically in UP Manila.

Key Words: cigarette price, youth smoking, stated preference, iterative bidding, discrete choice experiment, willingness to pay, willingness to accept

\footnotetext{
Paper presented and won 3rd Place at the 2nd UPM Research Competition, April 7, 2014, Philippine General Hospital, University of the Philippines Manila.

Corresponding author: John Paul Caesar R. delos Trinos

College of Public Health

University of the Philippines Manila

625 Pedro Gil Street, Ermita, Manila 1000 Philippines

Email: jrdelostrinos@up.edu.ph
}

\section{Introduction}

Smoking is the leading cause of preventable death worldwide. ${ }^{1}$ The youth comprises a significant portion of the smokers. $^{2} 29.6 \%$ of the 17.3 million smokers in the Philippines are between $15-24$ years old, ${ }^{3}$ with 18 years old as the average age of initiation. ${ }^{2}$

Not only is the prevalence of smoking high among the youth, they are also considered as among the most vulnerable group. The youth is exposed to various factors, such as peer pressure and ease of access to cigarettes, which could influence them to smoke. ${ }^{4}$ Early onset of smoking leads to higher chances of becoming a regular smoker. They also suffer from additional health burden such as impairment of lung development ${ }^{5}$ and effects on brain function. ${ }^{6}$ It was also found out that smokers in this age group are three times more likely than non-smokers to use alcohol, eight times more likely to use marijuana, and 22 times more likely to use cocaine. ${ }^{7}$ Thus, interventions must be implemented to protect the youth from the hazards of smoking.

Increasing the price of cigarettes through higher taxes is the single most effective way to decrease consumption and encourage users to quit. ${ }^{8}$ The youth, which includes college students, is among the most responsive group to increased prices of cigarettes because of their limited financial capacity. Studies suggest that the youth are two to three times more price-responsive than the general population. ${ }^{9}$ A study found that most young smokers in the Philippines said they will stop smoking if cigarette prices are increased to 10 pesos per stick. ${ }^{10}$

In 2013, the Sin Tax Law was implemented in the Philippines. However, more than a year after its implementation, the effect of the law on youth smoking is yet to be evaluated. A decrease in the incidence of smoking has not been observed despite the increased cigarette prices. ${ }^{11}$ There is a need to assess if the youth is indeed protected from the hazards of tobacco by this law through increased cigarette prices. One way of doing this is by determining the valuation of the youth for cigarettes and 
comparing it with the increased cigarette prices brought about by the Sin Tax Law.

Currently, there is limited research on cigarette valuation, most of which only utilized direct surveys which are found out to be unreliable. ${ }^{12}$ More reliable methods of determining cigarette valuation must be explored and utilized to come up with more accurate data. Accurate data are important in guiding policy makers in establishing the appropriate price for cigarettes.

This study aimed to assess the valuation for cigarettes among UP Manila students aged 18-24 through direct and indirect stated preference methods.

\section{Materials and Methods}

Stated Preference Methods were used in the study to determine the valuation for cigarettes among the youth, specifically among the college students of UP Manila. This is in light of the insufficient available data on price valuations for cigarettes among the youth or college students. Direct and indirect stated preference methods were used to allow comparison of the two methods, with the former being very flexible, ${ }^{13}$ easier to conduct and the more common method utilized in market research; while, the latter being the more reliable method of determining stated preference based from available literature. ${ }^{12}$

The study utilized a cross-sectional study design. It included UP Manila students aged 18-24 year-old as participants. The age group was selected because the youth is among the most vulnerable groups to smoking; with a significant proportion of smokers in the Philippines belonging to the 15-24 year old age group. ${ }^{2}$ Students below the age of majority were excluded due to ethical considerations.

Using a 95\% confidence interval, a frequency of $17 \%, 14$ and a total population of 3,310 UP Manila students aged 1824, ${ }^{15}$ the minimum sample size was computed to be 204 .

The participants were chosen through stratified random sampling. The population was stratified by college. A booth was set up in strategic areas of the colleges and systematic random sampling was done in each college. Using the sampling interval equation, the interval computed was 16 . Thus, every $16^{\text {th }}$ person who passed by the booth was asked if he/she is interested to participate in the study.

The sequence of data collection used in the study is as follows:

(1) Identification of the substitute product during the pre-testing of instruments,

(2) Obtaining the current retail prices of cigarettes, and

(3) Obtaining the WTP/WTA through direct and indirect stated preference methods.

Tangibility and comparability with cigarettes in terms of price, frequency of use, and utility for the product of the respondent were the criteria for selection of the substitute product used in the discrete choice experiment (DCE). The identification was done in UP Diliman during the pre-testing of the instruments. A total of 15 smokers were interviewed. All of them answered candies. Thus, candies, specifically Maxx menthol candies which are often sold alongside cigarettes by the street vendors, were identified as the ideal substitute product for cigarettes to be used in the DCE.

The brand specific retail prices of cigarettes were obtained from street vendors selling in the area bounded by Taft Avenue, Padre Faura St., Adriatico St. and Pedro Gil St. Total enumeration of all the street vendors in the specified area was done.

The interview schedule and the set-up for the DCE were developed using available references and in consultation with a professor of Health Policy, a Health Economist, and a proponent of the Sin Tax Law. ${ }^{16,17,18}$ The fixed budget given to the smokers was set at $\mathrm{PhP} 50.00$, an amount deemed as a realistic budget for a person to spend cigarettes and its substitutes on. The interview schedule and the set-up for DCE were pretested in UP Diliman, which was chosen considering the similarities of the socio-economic status of the students, the academic environment, and the campus policies with that of UP Manila. The procedures were standardized and structured in order to minimize potential bias in results. The data collectors were trained on the conduct of iterative bidding and DCE. They also performed a return demonstration after being trained. A designated person from the research team observed and supervised the conduct of data collection.

Prior to the data collection, informed consent of the participants was obtained. The stated preference methods were conducted through a one-on-one interview. The interview began with questions on the general profile of the respondent. The respondent was then asked about his or her smoking habits. If the respondent was identified to be a nonsmoker, the current retail prices of high- and low-priced cigarettes were provided by the interviewer. Iterative bidding was employed to determine the highest price at which the respondent will consider buying a cigarette. If he or she is not willing to pay any amount, inducements with known values were offered iteratively until the non-smoker is willing to accept and smoke a cigarette stick.

If the respondent was identified to be a smoker, iterative bidding was conducted to determine the highest price at which he or she is willing to pay for a stick of cigarette. The DCE followed after the iterative bidding. The respondent was given a fixed budget which he needs to allocate between two different products - cigarette and the substitute product that would yield the highest utility. The two products were assigned pre-determined prices. Prices were then changed and the respondent was asked to choose a new combination. The process was repeated a set number of times and the data were collected accordingly. Only the smokers participated in the DCE. 
The data were double encoded in pre-tested forms in Microsoft Excel to minimize errors in encoding.

Descriptive statistics were used to analyze the smoking habits of the population. Inferential statistics were utilized to determine the demand curves of the smokers using simple linear regression. The association of smoking status and allowance with the WTP was determined using Fisher's exact test. On the other hand, T-test was used to compare the two methods of stated preference. Descriptive statistics was computed using MS Excel 2010, and Inferential Statistics data was analyzed through STATA Version 12.

\section{Results}

The study included 212 participants. Most of the respondents $(81.60 \%)$ were between 18 and 21 years of age, with 19 being the most common age, accounting for $26.89 \%$ of the sample. There were approximately an equal number of males (48.11\%) and females $(51.89 \%)$.

Most of the respondents $(84.43 \%)$ belong to the lower allowance brackets with allowances ranging from $\mathrm{PhP} 0.00$ PhP 2,000.00 per week. 21\% have a weekly allowance of PhP 2,001.00-PhP3,000.00 while only 3\% have a weekly allowance of greater than $\mathrm{PhP} 3,000$. The socio-demographic profile of the participants is shown in Table 1.

Table 1. Socio-demographic profile of respondents $(n=212)$

\begin{tabular}{lr}
\hline Characteristics & No. (Percentage) \\
\hline Age & $47(22.17)$ \\
18 & $57(26.89)$ \\
19 & $37(17.45)$ \\
20 & $32(15.09)$ \\
21 & $23(10.85)$ \\
22 & $10(4.72)$ \\
23 & $6(2.83)$ \\
24 & \\
Sex & $102(48.11 \%)$ \\
Male & $110(51.89 \%)$ \\
Female & \\
Allowance per week & $85(40.09)$ \\
PhP 0 - PhP 1,000 & $94(44.34)$ \\
PhP 1,001 - PhP 2,000 & $26(12.26)$ \\
PhP 2,001 - PhP 3,000 & $7(3.30)$ \\
>PhP 3,000 & \\
\hline
\end{tabular}

$9.91 \%$ (21 of 212) of the respondents were smokers, 19 of whom $(90.48 \%)$ were light smokers (1-10 sticks per day) while only two were moderate smokers (10-20 sticks per day) (Figure 1). 13 of them smoked intermittently while only eight smoked regularly (Figure 2).

$90.48 \%$ (19 of 21) of the smokers prefer Marlboro while $23.81 \%$ (5 of 21 ) prefer Lucky Strike. $76.19 \%$ (16 of 21) of the smokers were loyal to a specific brand.

Through iterative bidding, the median WTP of the smokers determined is $\mathrm{PhP} 6.00$ with an interquartile range of PhP 5.00-PhP 10.00. The mean WTP is PhP 6.94 with a standard deviation of PhP 2.97. The DCE yielded a median
WTP of PhP 12.43 for smokers with an interquartile range of $\mathrm{PhP}$ 10.42-PhP 12.95. Its mean is PhP 10.54 with a standard deviation of PhP 4.84 (Table 2). The t-test yielded a p-value of 0.01 indicating the results of the iterative bidding and DCE were significantly different.

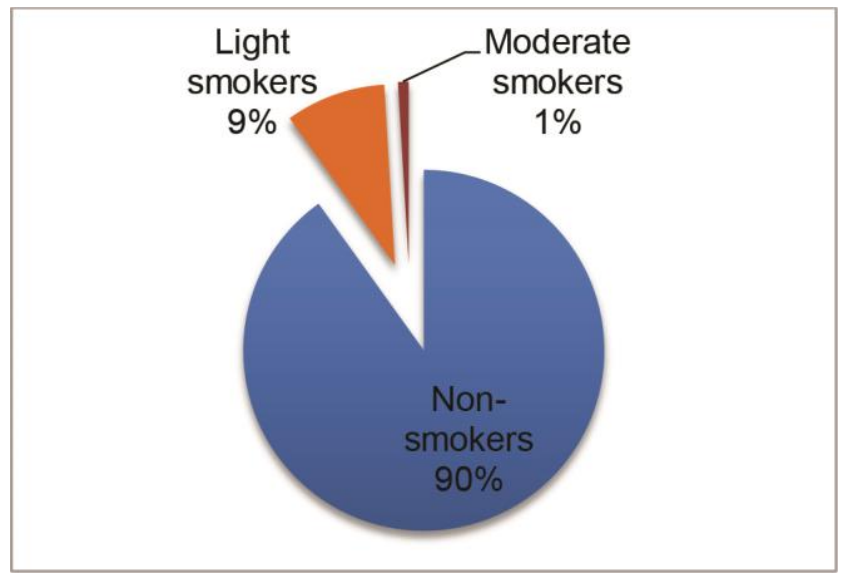

Figure 1. Smoking status of the respondents

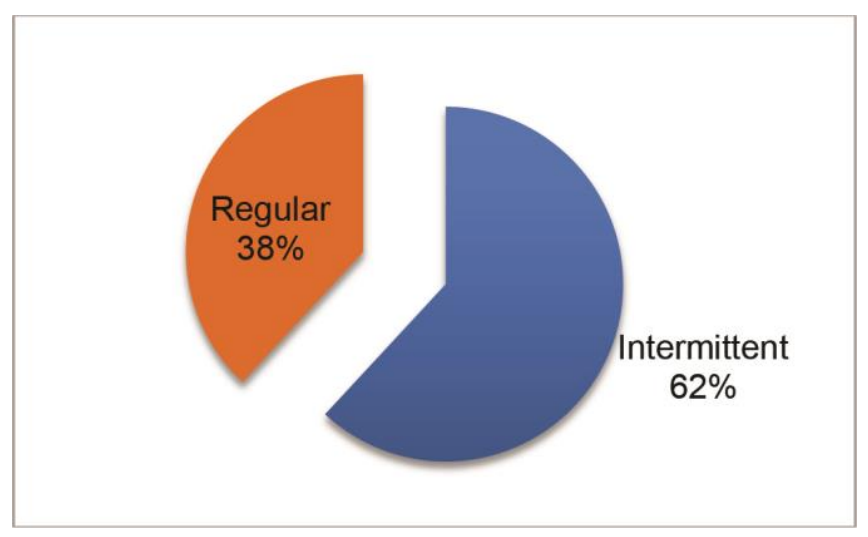

Figure 2. Classification of smokers based on smoking frequency

Table 2. Results of Iterative Bidding and Discrete Choice Experiment conducted among smokers $(n=21)$

\begin{tabular}{ccccc}
\hline $\begin{array}{c}\text { Stated Preference } \\
\text { Method }\end{array}$ & Mean & $\begin{array}{c}\text { Standard } \\
\text { Deviation }\end{array}$ & Median & $\begin{array}{c}\text { Interquartile } \\
\text { Range }\end{array}$ \\
\hline $\begin{array}{c}\text { Iterative Bidding } \\
\text { (Direct) }\end{array}$ & $\mathrm{PhP} \mathrm{6.94}$ & $\mathrm{PhP} \mathrm{2.97}$ & $\mathrm{PhP} 6.00$ & $\begin{array}{c}\mathrm{PhP} 5.00- \\
\mathrm{PhP} 10.00\end{array}$ \\
$\begin{array}{c}\text { Discrete Choice } \\
\text { Experiment } \\
\text { (Indirect) }\end{array}$ & $\mathrm{PhP}$ & $\mathrm{PhP} \mathrm{4.84}$ & $\mathrm{PhP} \mathrm{12.43}$ & $\mathrm{PhP} \mathrm{10.42-}$ \\
\hline
\end{tabular}

78 of the 191 non-smokers (40.84\%) were willing to smoke a cigarette given the appropriate inducement with a median WTA of PhP 0.00 . Thirty eight (19.90\%) of the nonsmokers were willing to pay for a stick of cigarette. The type of inducement $(58.62 \%, 17$ of 29$)$ and the unlikelihood of 
becoming addicted by smoking a single cigarette stick $(44.83 \%$, 13 of 29$)$ were cited as the two most common reasons for the willingness to smoke among the nonsmokers (Table 3).

Table 3. Reasons of non-smokers for their WTA

\begin{tabular}{lcc}
\hline \multicolumn{1}{c}{ Reason } & $\begin{array}{c}\text { Number } \\
(\mathbf{n}=\mathbf{2 9})^{*}\end{array}$ & Percentage \\
\hline Willing to try for the offered inducement & 17 & $58.62 \%$ \\
Just one stick/for the experience & 13 & $44.83 \%$ \\
Low price & 1 & $3.45 \%$ \\
Social influence & 3 & $10.34 \%$ \\
\hline *
\end{tabular}

*Only 29 of the non-smokers were asked this question

113 of the non-smokers $(59.16 \%)$ were not willing to smoke regardless of the inducement offered to them, citing their awareness of the health hazards of smoking (58.41\%, 66 of 113) as the most common reason (Table 4).

Table 4. Reasons of non-smokers without WTA for their refusal to try smoking

\begin{tabular}{lcc}
\hline \multicolumn{1}{c}{ Reason } & $\begin{array}{c}\text { Number } \\
\text { (n=113) }\end{array}$ & Percentage \\
\hline Health hazard awareness & 66 & $58.41 \%$ \\
Personal beliefs and principles & 30 & $26.55 \%$ \\
Fear of addiction & 20 & $17.70 \%$ \\
Bad odour & 12 & $10.62 \%$ \\
Existing health conditions & 12 & $10.62 \%$ \\
Upbringing & 9 & $7.96 \%$ \\
Smoking family member & 8 & $7.08 \%$ \\
Smoking family member got sick due to & 6 & $5.31 \%$ \\
smoking & & \\
Bad experience with smoking & 6 & $5.31 \%$ \\
Bad image & 6 & $5.31 \%$ \\
Health professional in family & 2 & $1.77 \%$ \\
Waste of money & 2 & $1.77 \%$ \\
\hline
\end{tabular}

The Fisher's Exact Test yielded a p-value of 0.74 between Smoking Status and WTP and 0.45 between allowance and WTP, indicating no significant association between the WTP of smokers and their allowance or smoking status.

41 street vendors selling cigarettes were interviewed, 21 of whom were located along Taft Ave., 12 along Padre Faura St., and eight along Pedro Gil St. The most expensive brand sold is Marlboro with an average price of PhP 4.65 per stick while the cheapest is Fortune at PhP 2.24 per stick. The average prices are shown in Table 5. It was noted that some vendors actually give additional discounts to students.

Table 5. Average Retail Prices of the Popular Cigarette Brands among Street Vendors

\begin{tabular}{ccc}
\hline Brand & Number of Vendors & Average Price \\
\hline Marlboro & 41 & PhP 4.65 \\
Philip Morris & 36 & PhP 4.44 \\
Winston & 38 & PhP 3.42 \\
Hope & 31 & PhP 3.29 \\
Fortune & 36 & PhP 2.24 \\
\hline
\end{tabular}

The vendors were also asked about the popularity of the various cigarette brands. $75.61 \%$ (31 of 41 ) of the vendors said that Marlboro is the most popular while $21.95 \%$ (9 of 41 ) answered Fortune.

The average retail price of Marlboro, which is $\mathrm{PhP} 4.65$ per stick, is 2.67 times lower than the median WTP of smokers which is PhP 12.43.

\section{Discussion}

Increasing the price of tobacco by raising its taxes is the single most effective way to decrease tobacco consumption and encourage tobacco users to quit. ${ }^{8}$ In determining the appropriate tax level imposed on tobacco products, it is important to assess the consumer's valuation for cigarettes which could be measured using WTP and WTA. To do this, stated preference could be employed. Stated preference is a group of methods that measures valuation through direct survey such as iterative bidding or indirect surveys such as a DCE. ${ }^{12}$

The study assessed the valuation of UP Manila students, aged 18-24, for cigarettes through direct (iterative bidding) and indirect (DCE) stated preference methods.

\section{Smoking Habits}

The smoking prevalence found among the sample $(9.91 \%)$ is almost 3\% less than the prevalence found in two UP Manila colleges in a previous study ${ }^{19}$ and $10.9 \%$ less than the prevalence in the same age group based on GATS 2009. ${ }^{2}$ Majority of them $(90.48 \%)$ were light smokers while the remaining $9.52 \%$ were moderate smokers. None were heavy smokers. 13 of them smoked intermittently while only eight smoked regularly. This low burden of smoking could be attributed to the characteristics of the study population since most of the degree programs offered in UP Manila are on health sciences and thus, the students are deemed knowledgeable on the effects of smoking. Knowledge on the harmful effects of smoking is one of the factors which could deter students from smoking. ${ }^{8}$ Unfortunately knowledge on the hazards of smoking and addicting nature of cigarettes may not be very high among the youth, specifically among teenagers. ${ }^{20}$

Majority of the smokers (90.48\%) used Marlboro despite its relatively higher price supporting reports that Marlboro still maintains a major share of the cigarette market ${ }^{21}$ despite the increased prices brought about by the Sin Tax Law.

Meanwhile, the increase in the sales of brands such as Lucky Strike and Fortune could be related to downshifting from premium to cheaper brands which is observed when increasing the prices of cigarettes in an ad valorem system. 22,23 This trend would be expected until 2017, the year at which uniform or specific tax rates will be imposed on cigarettes regardless of the market value. ${ }^{24}$

16 of the smokers $(76.19 \%)$ were loyal to one specific brand, consistent with other studies which state that 
smoking is brand-specific. ${ }^{25}$ This could be due to reasons such as taste and addiction to the brand. A study revealed that price is only second to the taste among the reasons of youth for choosing which brand to smoke. ${ }^{10}$ This holds true even amidst price increases especially if the increases are not sufficiently high.

\section{Direct Stated Preference}

Iterative bidding was utilized to determine the direct stated preference for cigarettes of the participants.

Among the smokers, it was found that half of the smokers in the sample were not willing to buy cigarettes if the price exceeds PhP 6.00 per stick, highlighting the effectiveness of increasing cigarette prices in decreasing tobacco consumption. This is especially true for the youth who were found to be two to three times more responsive to price changes in cigarettes compared to the general population. ${ }^{9}$

One key finding of the study is that $40.84 \%$ of the nonsmokers were willing to smoke a cigarette stick given the appropriate inducement. Half of them are willing to smoke if the cigarette stick was offered for free. Another finding is that $19.90 \%$ (38 of 191) of the non-smokers were even willing to pay for a stick of cigarette. This highlights the vulnerability of non-smokers to smoking; an issue that must be emphasized as most available literature relating the hazards of smoking to non-smokers only focus on second hand smoke.

When asked for reasons for their willingness to smoke despite their non-smoking status, majority (58.62\%) answered that they were enticed by the type of inducement offered. The inducement need not be very expensive. Determining the right kind of inducement can entice more non-smokers to smoke with less expense for the cigarette companies. On the other hand, $44.83 \%$ (13 of 29) said that they were willing to try because it was just a stick and that it will not make them addicted to cigarettes. This reflects the observed underestimation of the addictive effects of cigarettes by the youth. ${ }^{20,26}$.

The study also revealed that 59.16\% (113 of 191) of the non-smokers had no WTA and thus, were not willing to try a cigarette despite any kind of inducement offered. $58.41 \%$ of them cited their awareness of the health hazards of smoking while $26.55 \%$ cited their personal beliefs and principles as reasons for having no WTA. This shows that information campaigns on the adverse effects of smoking are effective in deterring non-smokers from smoking. These could be explored and utilized in improving tobacco control efforts.

Indirect Stated Preference

A DCE was utilized to obtain the indirect stated preference for cigarettes of the smokers. Using this method, it was found that half of the smokers in the sample were not willing to pay for cigarettes if the price reaches $\mathrm{PhP} 12.43$ or higher per stick.

DCE indirectly obtains the WTP of smokers for cigarettes. It puts less emphasis on the price and it provides a more realistic market scenario. For these reasons, DCE is preferred over iterative bidding and other contingent valuation methods in obtaining the stated preference. ${ }^{12}$

\section{Comparison of the Direct and Indirect Stated Preference Results}

Iterative bidding, which is the direct stated preference method utilized in this study, requires the respondents to directly state how much he or she is willing to pay for a specific product and is thus prone to biases. On the other hand, indirect stated preference methods, particularly the DCE, exhibit both higher internal and external validity. In this method, real purchasing behavior is simulated by giving the participants a fixed budget and asking them to spend the money on the specified products. This approach relies more on the accuracy and completeness of the characteristics used to describe the good, which lessens the emphasis on cost. ${ }^{12}$

The study found that the results of the indirect (DCE) were significantly different from that of the direct (iterative bidding) stated preference methods ( $p$ value $=0.01$ ). This is also evident in their means where the mean of iterative bidding ( $\mathrm{PhP}$ 6.94) is 1.52 times lower than that of DCE (PhP 10.54).

Thus, the result shows that there is an understatement of the stated preference of the participants for cigarettes using the iterative bidding. This bias could be attributed to the limitations of iterative bidding such as the unnatural focus on price, absence of information about the value of the different attributes that comprise the good, lack of incentive for the consumers in revealing their true valuation, unstable perceived valuations, and the inconsistency of the obtained valuation with the real purchasing behavior. ${ }^{12,27}$

It is interesting to note that iterative bidding and other contingent valuation methods are the preferred methodological approaches when facing monetary and/or time constraints, ${ }^{12,13}$ as is the case in many tobacco control studies. Unfortunately, data from these studies are used in guiding policy makers in adjusting the price of cigarettes. Clearly, there is a need to employ more reliable methods such as DCE in obtaining the valuation of the consumers for certain products.

Association of Factors with the Indirect Stated Preference of the Smokers

There was no significant association found between the stated preference for cigarettes of smokers and their allowance $(p$-value $=0.45)$. This goes against the available literature which states that the WTP is affected by socioeconomic factors. ${ }^{28,29}$ This inconsistency could be due to the insufficient number of smokers, the nature of the sample, and other factors that must be considered. Likewise, no 
significant association was found between the stated preference of the smokers and their smoking status ( $p$-value $=0.74$ ). This also goes against the assumption that smokers with a higher rate of consumption are more willing to pay for a greater number of cigarettes compared to groups with less consumption. ${ }^{30}$ Further studies are then recommended to explore these relationships.

\section{Current Market Retail Prices of Cigarettes}

All of the interviewed vendors sell Marlboro. Majority of the vendors (31 of $41,75.61 \%$ ) said that Marlboro is the most popular brand. This shows the brand's dominance in the market, despite the fact that it is the most expensive brand with an average price of $\mathrm{PhP} 4.65$ per stick. Fortune is the cheapest brand sold by the street vendors at an average of PhP 2.24 per stick. Nine of the interviewed vendors said that Fortune is the most popular brand and this is due to its cheap price.

\section{Comparison of the WTP of the Smokers with the Current Retail Prices}

The increased prices of cigarettes in 2013 brought about by the Sin Tax Law are insufficient in making the smokers quit the habit. In fact, cigarette prices in the Philippines are still low compared to other ASEAN nations. ${ }^{31}$ Also, the Sin Tax Law only achieved a tax burden of $53 \%,{ }^{31}$ which is below the recommended $70 \%$ by the World Health Organization. ${ }^{8}$ Thus, further increases in prices of cigarettes are needed to curb the tobacco epidemic. Aside from increasing the price, other strategies could be utilized in reducing tobacco consumption.

\section{Acknowledgments}

The authors would like to extend their deepest gratitude to Dr. Fely Marilyn Lorenzo and Dr. Hilton Lam for introducing and providing valuable insights in the conduct of stated preference studies and to Dr. Antonio Miguel Dans for providing comments and suggestions on making the study more relevant. They would also like to thank the faculty of the College of Public Health, University of the Philippines Manila (UP Manila) for sharing their insights and expertise which greatly helped in the development of the study.

\section{References}

1. World Health Organization. Tobacco Free Initiative [Online]. 2013 [cited 2013 Nov]. Available from: http://www.who.int/tobacco/ health_priority/en/.

2. National Statistics Office and Department of Health (PH). 2009 Philippines Global Adult Tobacco Survey. [Online]. 2010 Mar [cited 2013 Nov]. $135-137$ p. Available from http://www.who.int/tobacco/ surveillance/2009_gats_report_philippines.pdf.

3. World Health Organization Philippines. 2009 Philippines' GATS. March. $23^{4} \mathrm{p}$.
4. World Health Organization and Department of Health Philippines. A Training Manual for Health Workers on Healthy Lifestyle: An Approach for the Prevention and Control of Noncommunicable Diseases. 2009. 44 p.

5. Centers for Disease Control and Prevention. Preventing Tobacco Use Among Youth and Young Adults [Online]. 2012 [cited 2014 Nov]. 6-8 p. Available from http://www.cdc.gov/tobacco/data_statistics/sgr/2012/ consumer_booklet/pdfs/consumer.pdf.

6. University of California - Los Angeles. Tobacco smoking impacts teens' brains, study shows [Online]. 2011 Mar [cited 2014 Nov]. Available from www.sciencedaily.com/releases/2011/03/110302152820.htm.

7. World Health Organization. Tobacco Free Initiative [Online]. 2013 [cited 2013 Nov]. Available from http://www.who.int/tobacco/research/ youth/health_effects/en/.

8. World Health Organization. The Global Tobacco Epidemic 2013: Enforcing bans on tobacco advertising, promotion and sponsorship [Online]. 2013 [cited 2013 Nov]. 43-45 p. Available from http://apps.who.int/iris/bitstream/10665/85380/1/9789241505871_eng.pdf

9. Bader P, Boisclair D, Ferrence R. Effects of Tobacco Taxation and Pricing on Smoking Behavior in High Risk Populations: A Knowledge Synthesis [Online]. IJERPH 2011 Oct, 26; Volume 8(11):4118-4139 [cited 2013 Nov] Available from http://www.ncbi.nlm.nih.gov/pmc/articles/ PMC3228562/.

10. Health Justice Philippines. Smoking and the Filipino Youth [Online]. 2012 [cited 2013 Nov 07]. Available from http://www.healthjustice.ph/uploads/SWS\%20Fact\%20Sheet.pdf.

11. Bordadora N. Sin tax law ups revenues but has not cut down smoking. Philippine Daily Inquirer [Online]. 2013 July 3 [cited 2013 Nov 7]. Available from http://newsinfo.inquirer.net/437255/sin-tax-law-upsrevenues-but-has-not-cut-down-smoking.

12. Accent.Review of Stated Preference and Willingness to Pay Methods [Online]. Rand Europe. 2010 January [cited 2013 Dec]. 3-13 p. Available from http://webarchive.nationalarchives.gov.uk/+/http:// www.competition-commission.org.uk/our_role/analysis/summary_and_ report_combined.pdf.

13. Foreit J, Foreit K. Willingness to Pay Surveys for Setting Prices for Reproductive Health Products and Services. A User Manual [Online]. 2004 [cited 2014 Jan 01].

14. Laylo Research Strategies. The Weekly Report September 14, 2012. The Laylo Report [Online]. 2012 Sep [cited 2013 Nov]. Available from http://thelayloreport.files.wordpress.com/2012/09/the-weekly-numbersept2012_wk24.pdf.

15. Ramos-Mortel BT. Registrar (Office of the University Registrar, University of the Philippines Manila). December 2013.

16. Lam H. Director (Institute of Health Policy and Development). Personal communication. 7, 9 November 2013.

17. Lorenzo F. Professor (College of Public Health, University of the Philippines). Personal Communication. 11 November 2013.

18. Dans A. Cardiologist, Medical Professor (University of the Philippines Manila). Personal Communication. 15 November 2013.

19. Agosto HC, De Leon LL, Dumagpi JL et al. Prevalence of Smoking and Association of Social Influences with Smoking Behavior among Students from Two Selected Colleges of the University of the Philippines-Manila [Thesis]. College of Public Health, UP Manila. 2010.

20. Slovic P. Do adolescent smokers know the risk? [Online].1998 Oct 29 [cited 2013 Nov 7]. 1133-1141 p. Available from http://scholarship.law.duke.edu/cgi/viewcontent.cgi?article=1032\&conte $\mathrm{xt}=\mathrm{dlj}$.

21. Sayson I, Yap C. Tobacco Giant Fights Philippine Market Share Decline [Online]. Bloomberg 2014 Feb 12 [cited 2014 Nov 13]. Available from http://www.bloomberg.com/news/2014-02-12/tobacco-giant-fightsphilippine-market-share-decline.html.

22. Gonzales I. Sin tax forces smokers' shift to cheaper brands. The Philippine Star [Online]. 2013 Oct 2 [cited 2013 Nov 7]. Available from http://www.philstar.com/business/2013/10/02/1240337/sin-tax-forcessmokers-shift-cheaper-brands. 
23. Congressional Policy and Budget Research Department. Excise Tax: Emerging Options for Reform [Online]. 2011 Oct [cited 2014 Nov 13]. Available from http://www.congress.gov.ph/ cpbo/images/PDF\%20Attachments/

CPBRD\%20Policy\%20Brief/No.\%202011-10-\%20Excise\%20Tax.pdf.

24. Official Gazette (PH). Republic Act No.10351 [Online]. 2012 Dec 19 [cited 2014 Nov 13]. Available from http://www.gov.ph/2012/12/19/republic-act-no-10351/.

25. Dawes J. Cigarette brand loyalty and purchase patterns: an examination using US consumer panel data. University of South Australia (Abstract) [Online]. 2012 [cited 2013Nov 7]. 2 p. Available from http://ssrn.com/abstract=2126951.

26. Ross H, Chaloupka FJ. The Effects of Cigarette Prices on Youth Smoking [Online]. impacTEEN. 2001 Feb [cited 2013 Nov]. 2 p. Available from http://www.uic.edu/orgs/impacteen/generalarea_PDFs/pricepaperFebru ary2001.pdf.

27. Breidert C, Hahsler M, Reutterer T. A Review of Methods for Measuring Willingness-to-Pay [Online]. 2006 [cited 2014 Jan 01]. Available from http://businessperspectives.org/journals_free/im/2006/im_en_2006_04_B reidert.pdf
28. Boccaletti S, Moro D. Consumer Willingness-to-Pay for GM Food Products in Italy. AgBioForum [Online]. 2000 [cited 2013 Nov 7]. 5 p. Available from http://www.agbioforum.org/v3n4/v3n4a14boccaletti.pdf.

29. Ulimwengu J, Sanyal P. Joint Estimation for Farmers' Stated Willingness to Pay for Agricultural Services. International Food Policy Research Institute [Online]. 2011 March [cited 2013 Nov 7]. 9 p. Available from http://www.ifpri.org/sites/default/files/publications/ifpridp01070.pdf.

30. Cavaroz-Rehg PA, Krauss MJ, Spitznagel EL, Chaloupka FJ, Luke DA Waterman B, Grucza RA, Bierut LJ. Differential effects of cigarette price changes on adult smoking behaviours. US National Library of Medicine - National Institutes of Health [Online]. 2012 Nov. [cited 2013 Nov 7].3 paragraphs. Available from http://www.ncbi.nlm.nih.gov/pmc/ articles/PMC3740198/

31. Lian TY, Dorotheo U. The ASEAN Tobacco Control Atlas. First Edition. Southeast Asia Tobacco Control Alliance 2013 Aug. Bangkok, Thailand.

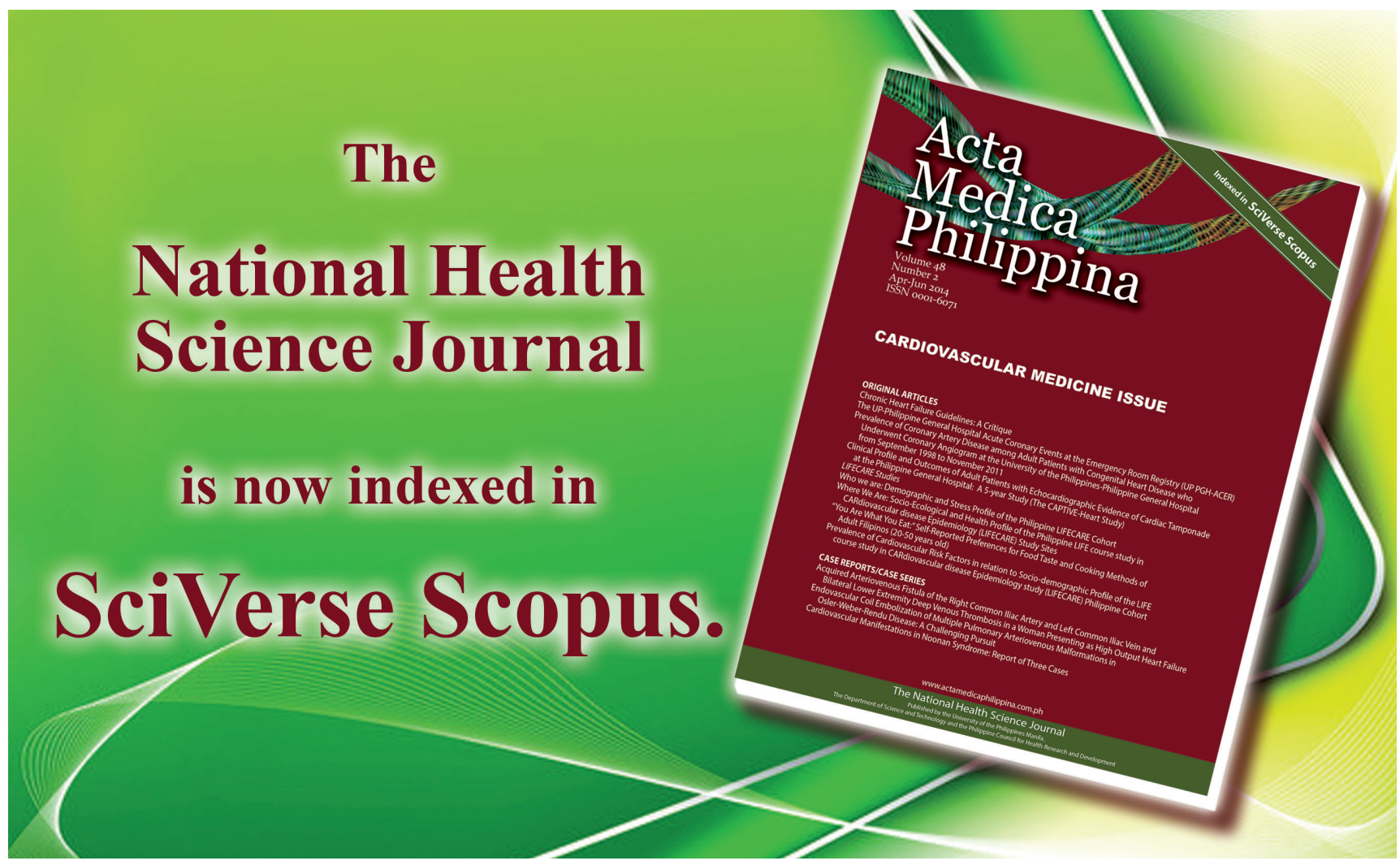

